STUDIES ON THE REGENERATION OF CRUSTACEAN APPENDAGES

BY

GERTRUDE MELLEN HOOPER

A. B. Jackson College, 1915.

THESIS

Submitted in Partial Fulfillment of the Requirements for the

Degree of

MASTER OF ARTS

IN ZOOLOGY

$1 \mathrm{~N}$

THE GRADUATE SCHOOL

OF THE

UNIVERSITY OF ILLINOIS

1918 



\section{STUDIES ON THE REGENERATION OF CRUSTACEAN APPENDAGES}

GERTRUDE MELLEN HOOPER

A. B. Jackson College, 1915.

THESIS

Submitted in Partial Fulfillment of the Requirements for the

Degree of

MASTER OF ARTS

IN ZOOLOGY

IN

THE GRADUATE SCHOOL

OF THE

UNIVERSITY OF ILLINOIS

1918 



\section{8 \\ H76 UNIVERSITY OF ILLINOIS}

THE GRADUATE SCHOOL

I HEREBY RECOMMEND THAT THE THESIS PREPARED UNDER MY SUPERVISION BY Gertrude Mellen Hooper

ENTITLED _. Studies_on the Regeneration of Crustacean Appendages.

BE ACCEPTED AS FULFILLING THIS PART OF THE REQUIREMENTS FOR THE DEGREE OF Arts.

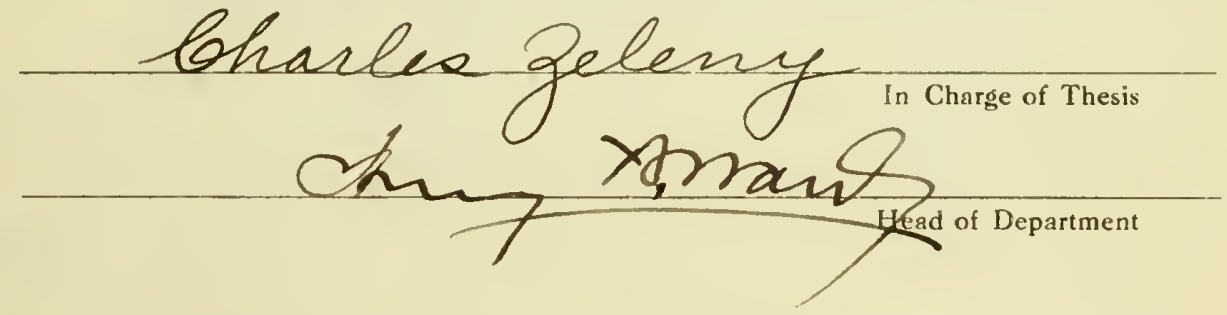

Recommendation concurred in*

Committee

on

Final Examination*

*Required for doctor's degree but not for master's 



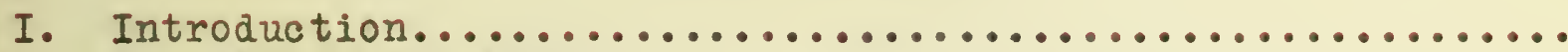

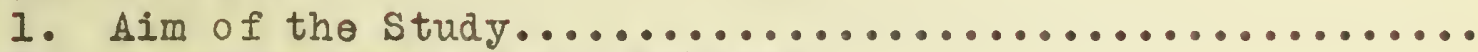

2. Previous Data on the subject...................... I

II. Material................................... 4

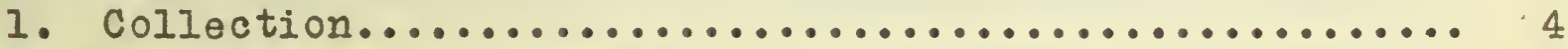

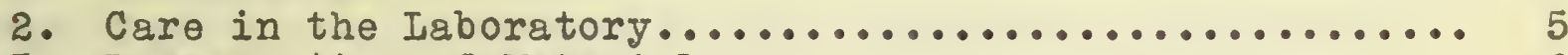

3. Preservation of Material........................ 6

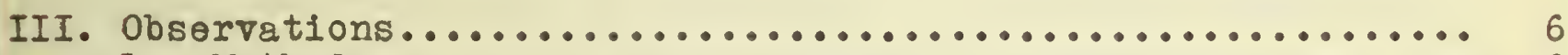

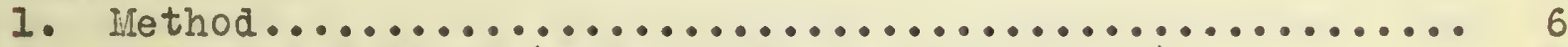

2. Data and Results (with Notes on Embryology)..........

A. Description of Regeneration in Chelate Legs........

B. " " "Non-chelate Legs....

C. " " " "Antennules.........

D. " " " "Antennae...........

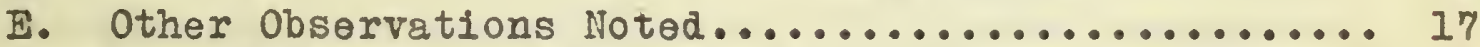

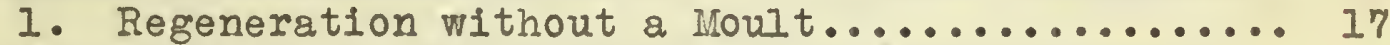

2. Comparison of the Rates of Differentiation in

the different Appendages................ I

3. Comparison of the Lengths of Regenerating and

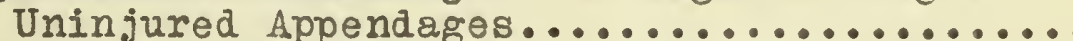

IV. Discussion................................ 20

. Summary.................................. 23

VI. Bibliography................................ 24

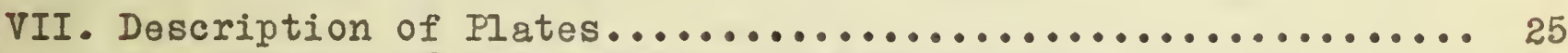

A. Process of Regeneration in Chelate Iegs............... 25

B. " " "Non-chelate Legs.............

26

C. " " " "Antennules................

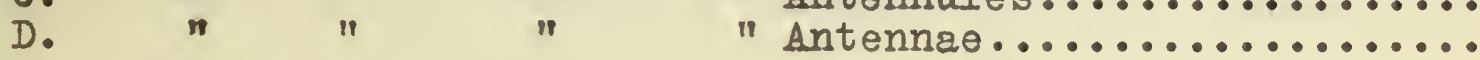



I. INTRODUCTION.

1. Aim of study.

The essential aim of the following study has been to determine whether or not there is any comparison between the embryonic and regenerative development of crustacean appendages, especially with regard to the direction of differentiation. The group of crustaceans was chosen because of the ease with which segmentation can be followed in these forms and the crayfish, Cambarus propinquus, was selected as it is a typical example of the Crustacea and could be readily obtained in the vicinity.

2. Previous data on the subject.

Holmes (1904), brought forth the theory that the direction of differentiation is a function of social pressure. By social pressure he meant "those influences from surrounding cells which tend to impress upon a part a certain structure and call forth a certain function." Holmes' belief concerning the direction of differentiation is well expressed in his own words, "Cells which develop in the direction of the missing part receive those advantages which the symbiotic relation afforded the cells whose place they take. Differentiation in any other direction deprives them of those advantages and subjects them to other unfavorable conditions. If the parts of an organism are so related that 
Digitized by the Internet Archive in 2014 
each derives greatest advantage from being situated where it is, It seems probable that if an organ were removed, the regenerating tissue which supplies its place and which we assume to be totipotent in its regenerative capacity, would differentiate most advantageously to itself in the direction of the missing organ." In other words, Holmes believes that the regeneration of an organ or part takes place from the base toward the tip. And he further states that he believes the general conception that differentiation begins in the distal end of a new structure is "out of harmony with our interpretation of the regenerative process." But such a view as Holmes put forward is readily seen to be purely theoretical and not based upon broad experimental evidence. It seems logical but does not bear experimental tests.

Child, (1906), brought forth an hypothesis which is based upon the same general principles as that of Holmes. According to each the regeneration of an organ or part is the result of functional activity or equilibrium, but Child does not accept the conception of a sort of symbiotic relation between the parts of an organism and believes that the organism is subjected to varying conditions of environment which tend to mould and remould the new tissue until, because of functional necessity, a part similar to the original is derived. His belief concerning differentiation is essentially, then, that the process begins at the tip and works backward toward the base since influences, largely external, work upon the surfaces of the new tissue, and create a current from without inward as a response to stimuli more or less similar to those to which the old part was subjected. 

The points of view of these two scientists, so nearly alike in their fundamental conceptions concerning the causes and results of the regulatory process, are just the opposite in their hypotheses as to the direction in which the process takes place. It may be seen, however, from the following papers that each was correct in his assumptions in so far as he went but that neither went far enough nor was sufficiently willing to admit the possibility of any other process taking place. Each was theoretical and not practical. That both processes may occur within the same organism is the evidence from the following papers based upon experimental observations.

The first study which definitely illustrates this fact was made upon the appendages of crustaceans by Zeleny. (1906), and his conclusions were verified by Haseman.

Zeleny was one of the first workers in the field of regeneration to observe that the direction of differentiation of regenerating tissue varies either from the base to the tip or vice versa during the first part of the process, and that the reverse order may take place later. His observations of the difference in the direction of differentiation were made upon the sow bug, Mancasellus macrourus, and he was able to determine the order of appearance of the segments in the developing antennule of this form. He found that normally the adult antenaule consists of ten or eleven segments (usually ten) and that the four basal segments are formed by a process of differentiation which begins at the base and travels irregularly outward, and that the remaining segments are formed by the reverse process, 

the terminal one being the first while the others follow in order from the tip inward.

Haseman, in his work upon the same form (Mancasellus mecrourus), the amphipod (Eucrangonax gracilis), and the orayfish (Cambarus propinquus) was able to determine more with regard to the nature of the direction of differentiation. To sumarize the work upon the crayfish, Heseman found that the direction of differentiation of the regenerating appendages is from the base toward the tip in the last two pairs of walking legs, and from the tip toward the base in the first two pairs of walking legs and the chelipeds, or the three pairs of chelate appendages in this species. That there seems to be some relation between the direction of differentiation and the resultant function is suggested by the early formation of pinchers in the case of the chelate legs.

Further studies of a similar nature but more extensive than have so far been carried on, are necessary in order to determine the exact nature of the processes involved, and to understand the significance of the factors which work to bring about the ultimate reestablishment of the lost part in its functional equilibrium.

\section{MATERIAI}

1. Collection.

The crayfish used in this study were collected in the fall and in the spring, at the latter time some females with eggs being found. These were hatched in the laboratory and 

the embryological development of the appendages was studied at different stages upon preserved material.

2. Care in the laboratory.

At first great difficulty was experienced in that many of the crayfish died and that for a long time no moults were observed. These individuals were collected in the fall of the year, late in september and in October, and in most cases no moult had occurred during the fall since the chitin was hard and distinctly seasoned. Theoretically, Cambarus propinquus moults twice a year after the first year, once in the fall from August to Ootober, and again in the spring, the males ordinarily in May and the females in June. Therefore the majority of individuals should have moulted soon after being brought into the laboratory. The difficulty of the frilure to moult and the frequent deaths oan only be explained on two scores; first, that the water in the dishes was too deep to permit the proper aeration of the gills; or, second, that the water supply at first used was too toxio in its composition.

The following method was found to eliminate much of the diffioulty. Each individual was kept in a separate dish, a flatbottomed glass bowl of finger bowl size, and given a number. The water in each dish was sufficient only to cover the back of the crayfish, and a small branch of the water plant, Elodea canadensis, was kept in each bowl. The crayfish fed upon this plant, upon bits of puffed wheat given on an average of once every four or five days, and from time to time upon bits of worm. The dishes were oleaned out every two weeks and a fresh supply of Elodea 

added. The University water, though hard, was found to be less toxic than the soft reservoir water of the building which, even after filtering contains minute particles of tar from the roof over which it arains. After the University water was used in place of the rain water, deaths occurred seldom and moults began to bo observed. For example, in one case an individual moulted first on March 19, and again on May 26; while in another case one moulted first on February 10, and again on April 2, indicating that the fall moult had been delayed and that the spring moult occurred earlier than the normal time. In the greater number of cases only one moult was observed, the majority of these taking place during January and February.

3. Preservation of Material.

Material for preservation was kept in $85 \%$ alcohol in individual vials, each with a slip of paper inserted which contained the necessary information for recognition. Many of the stages were mounted on slides in order to facilitate study, ospecially in the embryonic material. The regenorating stages wore usually completed upon the live crayfish. A diary was kept and arawings were made daily to record progress. The observations were made with the aid of a binocular microscope.

III. OBSERVATIONS.

1. Method.

The operations upon the individuals were performed with forceps or a pair of fine soissors. In the case of the chelipeds autotomy was caused by the crushing of the propodite with a pair 

of strong forceps. In the other operations fine scissors were used to out off the appendages. Cuts were made at different levels, and from some individuals only one of a pair of appendages was removed while from others both of a pair were removed. In addition to these operations, further injuries were sometimes inflioted since it has been found that added injuries, if not too great, induce more rapid regeneration. Each individual after operation was plaoed in a clean dish with fresh Elodea, in order to make the operation as prophylactic as possible, and no food was given for several days. In this way few deaths were attributed to infection in the wound.

2. Data and Results (with notes on Embryology).

A. Description of Regeneration in Chelate Legs. (Plate A). Chelipeds. The regenerating tissue of the cheliped appears about 10 or 12 days after the operation as a bluntly rounded tip of whitioh tissue which breaks through in about the midale of the surface of the scar of the basipodite. This tissue bulges out, finger-like at first, and is smooth and straight sided (Fig. 1). The process constantly grows longer (Fig. 2) until eight days after the first appearanoe of now tissue a faint groove is observed running longitudinally for about half way from the tip towards the base (Fig. 3). This groove seems to be formed by a depression of the outer layer, and is the first indication of differentiation, as it clearly suggests the chelate tip of the normal appendage. Elongation of the entire mass of the differentiating tissue continues and the groove becomes more prominent until three days later (Fig. 4) the straight smooth 

sides of the appendage begin to show differences in thickness, there being at first two constrictions, the more distal one on a level with the end of the groove, which approximately divides the new tissue into three recognizable regions of nearly equal length and thickness. No definite partitions are yet formed but the appendage elongates and a third constriction appears, while the line of the groove is turning to one side in the region of the distal constriction (Fig. 5). After three days this partition is complete (Fig. 6) and the first segment, the dactylopodite, completely differentiated. With further elongation the partition between the second and third segments, the propodite and the carpopodite, becomes complete (Fig. 7). A fourth constriction gives the appendage its normal number of segments and within two days the partitions between the third and fourth segments, the carpopodite and the meropodite (Fig. 8), and between the fourth and the fifth segments, the meropodite and the ischiopodite (Fig. 9), are formed. With the formation of this last partition the cheliped becomes completely differentiated and the process of regeneration is at an end sixteen days after the first appearance of new tissue.

The regenerative process in the formation of the chelipeds follows the process of embryonic development closely. The appendages are formed in the embryo as bud-like outgrowths of the somites which rapidly grow and undergo differentiation. As the appendages elongate, they fold up over the abdomen and are directed forward towards the cephalic lobes. Differentiation of the ombryonic tissue begins at an early stage. Steps in the differentiation can be detected which resemble the steps in regeneration; 

at first only the chelate tips have been derived, the remainder of the tissue being an irregular stalk of undifferentiated tissue long enough to become the entire appendage. A little later, embryos show evidence of constriction to form other segments and these become partitioned off in much the same manner as that described for the regenerative process. The tip segments, the dactylopodite and propodite, are very large, at first much larger than the rest of the appendage, and while there is no doubt as to the ultimate structure, nevertheless the whole appendage is an awkward looking organ and shows little definite plan. As time goes on, however, and the other segments are partitioned off the whole appendage loses its awkward heaviness and irregularity, and becomes a well-formed organ with every evidence of functional capability.

In both the embryonic and regenerative development the segments of the chelipeds are differentiated from the tip towards the base and the two processes take place in essentially the same manner.

Ist and 2nd Walking Legs. The process of regeneration in the first and second walking legs is specifically the same as that for the regenerating cheliped. These legs like all chelate appendages, are differentiated from the tip towards the base. It is interesting to note that while regeneration is going on the appendages are almost as thick as those of the chelipeds although In the normal adult condition the chelipeds are much heavier and stronger, and the chelae many times larger.

The direction of differentiation in the embryonic development of these legs is the same as that of the chelipeds. 

B. Description of Regeneration in Non-chelate Legs. (Plate B). 3rd and 4th Walking Legs. The non-chelate appendages, the third and fourth pairs of walking legs, develop in a different manner from that of the chelate appendages but in a similar manner to each other. A description of the process of a third walking leg will be given as an example. In the first place new tissue appears later than in the case of the chelate legs (about two weeks after the operation) and the first observation shows a blunt, squarely ended bulge of tissue slightly longer than wide (Fig. 1), in about the center of the scar surface of the basipodite. Two days later (Fig. 2) this process of new tissue has elongated sufficiently for differentiation to begin, and a little later (Fig. 3) a constriction appears transversely through the middle, while the terminal end remains blunt and squared. During the three days following the apperance of this constriction, elongation has continued and a seon nd constriction appears distal to the first and, like the first, leaving the end blunt (Fig.4). On the eighth day after the appearance of new tissue (Fig. 5) three such constrictions and four thickened regions are evident and a narrow hook-like tip begins to be formed (Fig. 5). At this time the basel segment becomes partitioned off and the constriction between the second and third, the meropodite and the carpopodite, begins to deepen (Fig. 7 ). From the eighth to the tenth day the partitions are formed through the constricted regions from the base towards the tip (Fig. $7,8, \& 9$ ). At the end of this time the process of differentiation is complete and the five segments of the normal non-chelate walking log are formed, 1. $\theta$. ten days after the appearance of new tissue, in considerably 

less time than is required for the chelate legs.

The third and the fourth walking legs start their embryonic development in the same way as do the other appendages, 1. $\theta_{\bullet}$, as bud-like outgrowths of the somites. Those outgrowths which go to form the third and fourth walking legs, develop into slim stalks of tissue long enough to form the entire appendage just as in the arse of the chelate legs. They show regular smooth sides for some time, the terminal end being rounded. The first evidence of differentiation is near the proximal end, when a slight constriction is noticeable; at a little later stage, further differentiation has gone on and three basal segments and a long terminal segment are distinguishable. The last stage observed before complete segmentation shows four basal segments and a tip narrowing slightly on one side to form a hook-like dactylopodite. These appendages never show the marked irregularity in contour shown by the chelate appendages. Thus, differentiation proceeds from the base toward the tip in both the embryonic and regenerative developments, and the regeneration of the lost appendage takes place by a series of processes similar to those passed through in the embryo.

The non-chelate legs differentiate from the base towards the tip while in the chelate legs the segments are formed from the tip inward. Whereas in the third and fourth walking legs the first bulge of new tissue is normelly blunt, in the chelipeds and first two pairs of walking legs the first tissue is rounded over at the terminal end. From the very beginning, therefore, the processes of regeneration for the chelate and the non-chelate 

legs are different, and differentiation takes place in opposite directions.

C. Description of Regeneration in Antennules. (Plate C). In forty crayfish observed the number of segments in the adult antennules varied from 18 to 31 in the inner ramus, and from 18 to 29 in the outer ramus. The inner ramus usually contained one more segment than the outer, and was shorter and more slender.

The regenerating antennule, on the other hand, generally showed that the outer ramus has one more segment than the inner ramus but that the length and thickness have the same proportion to each other as in the adult. Wile the observations so far made have not been extensive enough to be conclusive, they are sufficiently suggestive to warrant discussion.

Fig. I shows a pair of regenerating antennules in which the inner rami are short, the left showing only one blunt segment, and the right showing one rather long basal segment and a short second segment. The outer rami of the pair show four segments each, with constrictions in the basal segments which seem to indicate possible divisions here later. The tip segments suggest further segmentation but in an inward direction. But in Fig. 2 the inner ramus shows only one definite segment with two constricted regions, the tip of which appears normally rounded suggesting that differentiation takes place in only one direction here,- from the tip inward. The outer ramus shows four segments; the tip is short and does not, as in Fig. I, show any indication of further segmentation. The third segment is longer than the 
others, and possibly indicates a region of differentiation. In Fig. 3, Iikewise, the inner ramas shows a long third segment which seoms to be evidence that the three basal segments are formed and then the tip, and that further segmentation takes place through the growth and differentiation of the third segment. The outer ramis, however, contains five segments, the third a trifle longer than the others, and a pointed tip which seems to indicate that further segmentation will occur in an inward direction. The long unsegmented tip of the inner ramus is present in Fig. 4 but the third sogment is not noticoably longer than the rest. The outer ramus shows constrictions in both the tip and basal segments indicating differentiation in both directions. The other figures show much the same conditions and, seem to indicate that differentiation at first takes place from the base towards the tip, and later in the opposite direction. The majority of cases of the inner ramus show a long third segment, and of the outer ramus a constricted basal segment. Thus, there is a poseibility that change in direction of differentiation in the two branches of a single antennule takes place at aifferent levels. However, it is clear that differentiation in both directions occurs in all cases.

The two divisions of the antennule are present in very early stages in the embryonic development and remain of nearly equal size and length up to the time of hatching. Early stages show the bifurceted ends but no segments. Of the five segments present in the outer ramus at hatching only the tip segment shows evidence of further segmentation. The inner ramus bears 

four segments at the time of hatching, the terminal one being distinctly a tip segment but bearing no evidence of further differentiation. The third segment is no longer than the rest at this stage but just after hatching this segment does appear to be longer than the others. Therefore, the stages of the embryonic development, also, although incomplete, suggest that differentiation in both directions takes place, - at first in an outward direction and later from the tip inward. The exact level at which this change takes place could not be determined upon the material at hand.

D. Description of Regeneration in Antennae (Plate D). When the antennae of the crayfish are cut off, the cut surface heals over and no evidence of regeneration can be observed until after the first moult. Then the new appendage shows a varying number of segments but, although a general observation would lead to the conclusion that the appendage, as a whole, has been unfolded from a mass of regenerative tissue folded up within the scar, this could not be corroborated because no individuals were observed in the process of moulting •

The general structure of the regenerating antenna is interesting. As may be seen from any of the figures, the normal annulated character of an adult antenna varies in degree of completeness in the regenerating stages but there is a regular sequence of indications that a process of annulation will result in all cases. The typical regenerating appendage has one distinct basal segment with a short second segment. The third segment is in all cases longer than the rest and with a varying number of 

incomplete grooves running transversely inward for short

distances from the outer edge, at intervals of from two to three to the segment. Fig. I shows an antenna whioh for some reason did not become differentiated before the moult and, therefore, shows only a blunt stalk of tissue with apparently three recognizable segments, although no partitions are formed. In Fig. 2 the first two segments are clearly partitioned off but the remainder of the filament of the flagellum shows only a series of transverse grooves. No definite third segment is recognizable. The first three segments in Fig. 3, however, are distinct, the third belng very long and marked off by two well-defined grooves, with two short depressions interpolated in the middle of the distal two annulations indicated by these grooves. The flagellum, though not definitely annulated, shows the two kinds of grooves in the proximal part. In Fig. 4 the usual well defined grooves of the antenna seem to be definite partitions and only those depressions are present which, by their regularity, suggest that interpolation as well as differentiation in an outward direction will take place. In Fig. 5 differentiation from the base toward the tip is indicated for some distance but the long unsegmented terminal end provided with a pointed tip suggests a change in the direction of differentiation, since slight oonstrictions are present. Segmentation after this manner may also be recognized in Figs. 2,3,4,6,\& 7 . Fig. 6 shows the normal three basal segments of the flagellum, the third segment being long and of the ordinary appearance but bearing neither grooves nor depressions. The interpolated depressions described above can be seen on two of the segments, the fifth and sixth, and the tip segment shows 

indication of inward differentiation. Fig. 7, a much folded and curled structure, shows no long third segment but depressions upon the surface of the other segments are present, and further differentiation of the tip can be recognized. The most perfectly formed of all the flagella observed is shown in Fig. 8 as seen immediately after the first moult. No interpolated depressions can be noted and only one groove is indicated upon the long third segment. These observations show that the flagellum of the antenna of the crayfish begins to regenerate from the base toward the tip, as is suggested by the facts that the first two segments never show signs of further differentiation and that the third segment bears incomplete grooves. But at this level the direction of differentiation is reversed and this process is accompanied by interpolation of segments as indicated by the series of short depressions running transversely across the middle of various segments.

The exopodite of the antenna, a broad scale-like plate, is readily replaced and no cases of incomplete regeneration were observed.

The antenna of the crayfish shows the two divisions, the endopodite and the exopodite, early in the history of the embryonic development of the appendage. The endopodite grows as a long, thin, unannulated filament showing no indication that anything more than a whip-like organ will be derived. While the crayfish is still within the egg case, however, about thirty segments or annulations are developed. Slight constrictions along the filament, most decided near the base, constitute the first indication of annulation. The segments as they form are 

longer than broad; later, each shows a slight constriction near the middle, a condition which is repeated in the regenerative process and which suggests the addition of segments by interpolation. The third segment of the developing antenna was never distinctly reoognized to be longer than the others, although suggestions of incomplete segmentation in this region have been observed. The tip is very often long and unsegmented but it is evident from the notched appearance that further differentiation in an inward direction will take place.

It is observed from this study that the embryonic and regenerative processes follow the same plan, and that differentiation in both directions and interpolation of segments are all factors in the annulation of the fagellum of the crayfish antennae. E. Other Observations Noted.

1. Regeneration without a moult. As a general rule in cases of removal by cutting, the appendages do not regenerate until after the moult although, in rare instances, regeneration does take place. In case autotomy is caused, regeneration before the moult is the usual occurrence and the regenerative process follows the same general pattern as that observed after the moult.

2. Comparison of the Rates of Differentiation in the different Appendages. Varying lengths of time are required for the differentiation of the new tissue. By removing the cheliped and four walking legs from one side in several individuals it was possible to determine which of these appendages regenerates most rapidly. Unless regeneration starts to take place before the moult it is not possible to determine the order of segmentation in the appendages since differentiation has been going on within 

the scar of the old tissue and, upon being released by the moult, the new tissue usually shows complete segmentation. Citing the case of an individual in which the removal of all five appendages was made by autotomy, it was found that the tissue of the cheliped, first, third, and fourth walking legs appeared before the moult. The second walking leg did not appear until after the moult and was perfectly differentiated at that time. The new tissue appeared in the following order,- first walking leg, cheliped, third, and fourth walking legs before the moult and the second walking leg after the moult. Complete differentiation, however, took place in approximately the reverse order,- fourth, third, first walking legs, and cheliped. Table I shows the condition before the moult and indicates the time in days after the removal until the first tissue appeared, and the successive days thereafter when the segments were distinctly partitioned off. It will be seen that in the fourth walking leg, in which the regenerating tissue appeared latest, the differentiation and complete segmentation took place in the shortest time. Thus, while the new tissue appeared in order from the chelate to the non-chelate legs, complete segmentation took place in the reverse order,- from the fourth walking 1 og forward. 

Table I.

\begin{tabular}{|c|c|c|c|c|c|c|c|}
\hline \multirow{2}{*}{\multicolumn{2}{|c|}{$\begin{array}{l}\text { New Tissue } \\
\text { Appeared }\end{array}$}} & \multicolumn{6}{|c|}{ Days after the Appearance of New Tissue. } \\
\hline & & $\begin{array}{l}\text { First } \\
\text { segment }\end{array}$ & $\begin{array}{l}\text { Second } \\
\text { segment }\end{array}$ & $\begin{array}{l}\text { Third } \\
\text { segment }\end{array}$ & $\begin{array}{l}\text { Fourth } \\
\text { segment }\end{array}$ & $\begin{array}{l}\text { Fifth } \\
\text { segment }\end{array}$ & $\begin{array}{l}\text { Complete } \\
\text { segmenta- }\end{array}$ \\
\hline Cheliped & $\begin{array}{l}\text { 13th } \\
\text { Day }\end{array}$ & 8 & 11 & 14 & 16 & 16 & 16 \\
\hline $\begin{array}{c}\text { Ist } \\
\text { Walking } \\
\text { Ieg }\end{array}$ & $\begin{array}{l}\text { 10th } \\
\text { Day }\end{array}$ & 5 & 8 & 11 & $13-14$ & $13-14$ & $13-14$ \\
\hline $\begin{array}{c}\text { 3rd } \\
\text { Walking } \\
\text { Ieg }\end{array}$ & $\begin{array}{l}\text { 15th } \\
\text { Day }\end{array}$ & 10 & 10 & 8 & 5 & 2 & 10 \\
\hline $\begin{array}{c}4 \text { th } \\
\text { Walking } \\
\text { Ieg }\end{array}$ & $\begin{array}{l}\text { 16th } \\
\text { Day }\end{array}$ & 10 & 10 & 6 & 4 & 1 & 10 \\
\hline
\end{tabular}

3. Comparison of the Lengths of Regenerating and Uninfured Appendages. Complete segmentation of a new appendage takes place while the part is still comparatively small, i. e., from one fifth to one fourth the length of the normal appendage. In one case ( $\mathrm{Table}$ II) in which the appendages were completely differentiated before the moult, observations concerning the lengths of these and the normal appendages of the other side before and after the moult were taken. No change in the length of the normal appendages could be detected whereas the new appendages doubled their length after the moult.

Table II.

\begin{tabular}{|c|c|c|c|}
\hline & \multirow{2}{*}{$\begin{array}{c}\text { Unoperated } \\
\text { Side }\end{array}$} & \multicolumn{2}{|c|}{ New Appendage } \\
\hline & & Before moult & After \\
\hline Cheliped & $20 \mathrm{~mm}$. & $6 \mathrm{~mm}$. & $12 \mathrm{~mm}$. \\
\hline $1.8 t$ & $13 \mathrm{~mm}$. & $5 \mathrm{~mm}$. & $10 \mathrm{~mm}$. \\
\hline $3 r d$ & $15 \mathrm{~mm}$ & $4.5 \mathrm{~mm}$. & $9 \mathrm{~mm}$. \\
\hline $4 \operatorname{th}$ & $12 \mathrm{~mm}$. & $3 \mathrm{~mm}$. & $6 \mathrm{~mm}$. \\
\hline
\end{tabular}



IV. DISCUSSION.

From the above data it is evident that differentiation may take place in different directions in the different types of regenerating appendages and that there may even be a change in the direction of differentiation at different levels within the same appendage.

Zeleny (1904) determined that in both the ontogenetic and regenerative development of the antennule of the sow bug, the order of appearance of the segments is from the base outward in the four basal segments and that, thereafter, the order is reversed and takes place from the tip inward, until the normal adult ten or eleven segments are formed. The results of the present study corroborate the evidence of Zeleny, but the region of change in direction is the third segment of the crayfish and in this form the normal adult antennules are bifurcated and contain about twenty segments in each rams. It is clear that a change in direction takes place, but why does it take place? The formation of a tip segment early in the development suggests the assumption of functional activity since the antennules are feelers and hence, very sensitive in the tips.

Haseman's work upon the same form (1907) contains the same sort of evidence for the regenerating antenna, but here the change in direction takes place at the sixth segment, the $\mathrm{X}$ segment as he calls it, and the remaining segments are derived from this segment from the tip inward. No matter where the cut is made the $X$ segment is brought into action in supplying new segments. In the crayfish it is difficult to determine the 

exact region of change in direction but it is evident that at least two basal segments and an undifferentiated mass of tissue distal to these are formed in an outward direction. A long third segment, always present, even if there are distinct segments distal to this region, suggests a condition like that of the $X$ segment of Mancasellus. Other segments beside this one divide, and differentiation by interpolation is an added factor in the development of the antennae of the crayfish. The place at whioh the direction of differentiation changes from the base outward to the tip inward, seems, in the case of the antenna, also, to be the level at which the new appendage begins to function.

Further work upon these two appendages has been done upon the amphipod by Haseman (1907) who observed the change in structure to take place at the end of the third segment in both antennules and antennae. In this crustacean, the fourth segment is determined to be the $\mathrm{X}$ segment, from which first the tip and then the remaining segments are derived. This condition is more nearly like that of the crayfish, although these antennae have the added character of interpolation of segments by the transverse splitting of any or all of the segments except the two basal ones.

The experimental work upon the walking legs of the Crustacea is uniform in its evidence that the non-chelate legs regenerate from the base toward the tip and that the chelate appendages regenerate in the reverse direction. From the experiments of Haseman the legs of the amphipod and sow bug are found to regenerate from the base toward the tip, but these are non-chelate or clawed legs. In the crayfish the non-chelate 

third and fourth walking legs differentiate in this direction; but the chelate legs, in exactly the opposite direction, the pincher-like tip being formed first. The function of these two types of legs is different. The chelate legs are organs for seizing and holding food and the early formation of the chelae suggests that functional demand for the reestablishment of the lost appendage takes place in the direction of the formation of the most useful part first. In the non-chelate legs no such function is demanded. Here the appendages are used as supports to hold the body of the crayfish off the substratum, or to aid in pushing the animal along in walking. Hence, the greatest strain comes near the base of these legs and this part is first acquired in the regenerating appendage. The claws have a secondary function and are not essential to the achievement of the highest efficiency in the organism.

The theories of Holmes and Child agree that the regeneration of a lost part is the attempt made by the organism to get back to a functional equilibrium (an hypothesis which seems to be strengthened by experimental data) but their beliefs with regard to the nature of the processes undergone in the reconstruction of the part and the direction in which appendages differentiate, have been overthrow by the experimental evidence of the work of Zeleny, Haseman, and by the present study. 

V. SUMMLARY.

1. The direction of differentiation of the segments in the regeneration of the appendages of the craytish is the same as that in the embryonic development. One striking difference not involving direction was noted, that the embryonic tissue gains length before differentiation begins, while the regenerative tissue differentiates as it elongates.

2. The oheliped and first two pairs of walking legs differentiate from the tip toward the base.

3. The non-chelate legs regenerate in the opposite direction,from the base toward the tip.

4. The antennules regenerate from the base toward the tip at first but later new segments are supplied by the division and growth of a long third segment, and by differentiation of the tip in an invard direction.

5. The antennae of the crayfish regenerate at first from the base toward the tip as indicated by the two well-defined basal segments; later segmentation takes place by differentiation from the tip inward and by interpolation, i. e. by the transverse splitting of any or all of the segments except the two basal ones.

6. As a rule regeneration of an appendage removed by cutting does not take place before the moult but in cases of autotomy regeneration frequently progresses to the extent that all the segments are formed before moulting.

\section{Acknowledgement.}

My sincere appreciation is expressed to Dr. Zeleny for his aid and suggestions throughout the experimental work. 

VI. BIBIIOGRAPHY.

Child, c. I.

1906. Contributions toward a Theory of Regulation. Arch. 1 . Entw. Mech., 20: 380-426.

Haseman, J. D.

1907. The Direction of Differentiation in Regenerating Crustacean Appendages. Arch. 1 . Entw. Iriech., 24: $617-637$.

Holmes, S. J.

1904. The Problem of Form Regulation. Arch. f. Entw. Mech., 17 : $265-305$.

1907. Regeneration as Functional Adjustment. J. Exp. Zool., 4: $419-430$.

Huxley, T. H.

1906. The study of zoology illustrated by the Crayfish. N. Y. : $356 \mathrm{pp}$.

Ortmann, A. I.

1905. Crawfishes of the state of Pennsylvania. Liemoirs of the Carnegie Museum, 2: 358-365; 410-413.

Reed, Margaret $A$.

1904. Regeneration of the First Ieg of the Crayfish. Arch. f. Entw. Mech., 18: 307-316.

Zeleny, Charles.

1906. Direction of Differentation in Development. Arch. f. Entw. Liech., 23: 324-342.

1907. The Embryological Significance of the Direction of Differentiation in Regenerating Appendages. Froc. Seventh Intorn. Z001. Congress. 1907: 495-496.

1916. Studies on the Factors controlling the Rate of Regeneration. III. Biol. INonographs, 3, No. I: 9-25; 61-107; 158-166. 



\section{Plate 7}
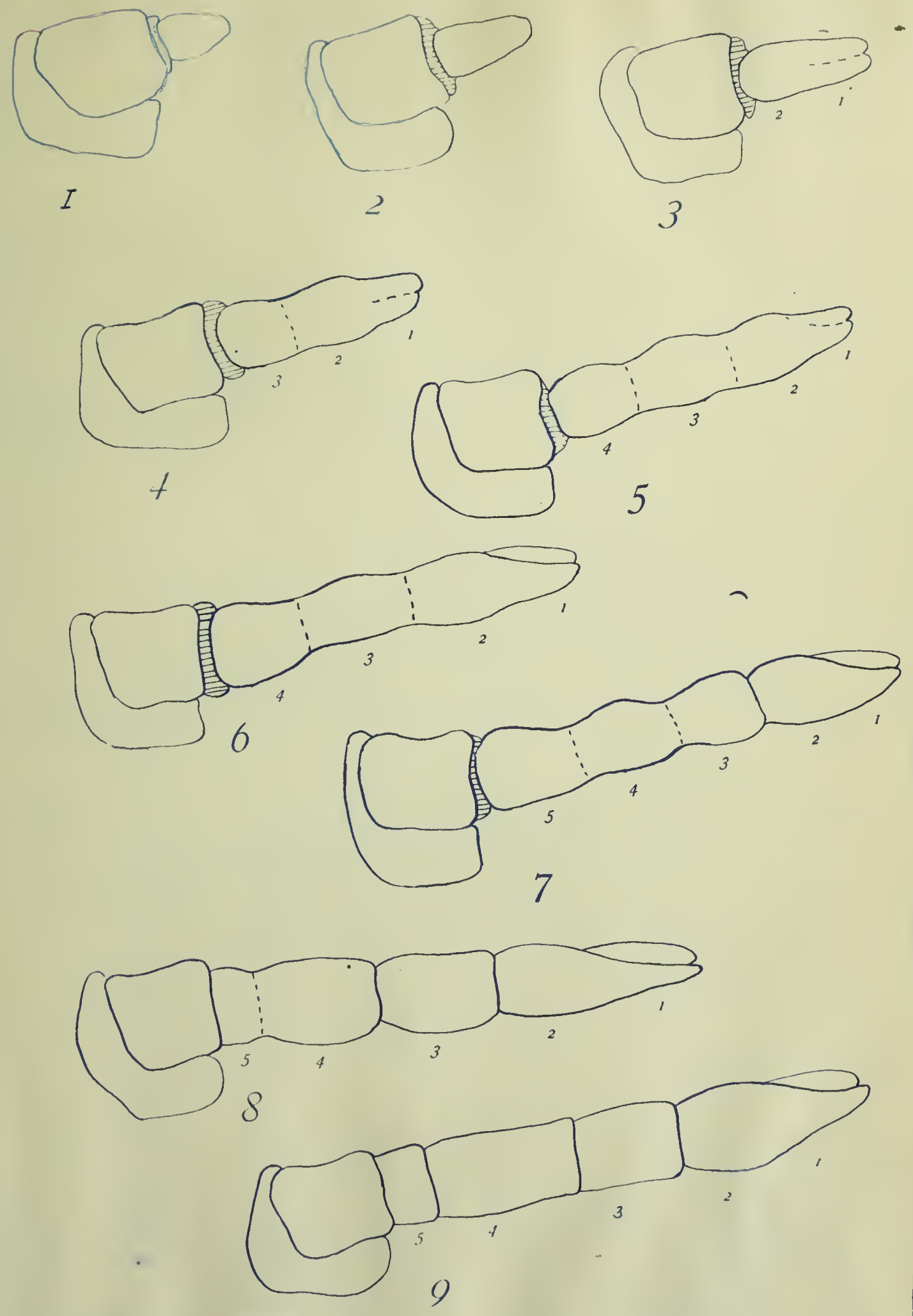

Plate B. Process of Regeneration in Non-chelate Iegs.

Description of Figures 1 to 9 .

The region crossed by black lines represents the cut surface or scar and the two segments shown proximad of this are the basipodite and coxopodite of the appendage. The bulge of new tissue breaks through in about the midale of the scar surface. The segments are numbered in the order of their appearance.

1. First bulge of now tissue, fifteen days after operation, blunt and square-ended.

2. Elongation of new tissue during next two days and constriction appeering in the midale to suggest two segments. Tip still biunt.

3. Constriction clearly indicating two segments to be formed later.

4. Three days later than Fig. 2, showing two constrictions and three thickened regions.

5. Further elongation and constrictions to indicate four segments but with the terminal end still blunt.

6. During three days following Fig. 4, joint between segments 1 and 2 almost complete and the tip beginning to appear pointed. Differentiation complete.

7. Partition between segments 1 and 2 complete and between segments 2 and 3 evident.

8. The following day partition between segments 2 and 3 complete and between segments 3 and 4 evident.

9. Segmentation completed next day, i. e. tenth day after first appearance of new tissue. 



\section{Plate $B$}
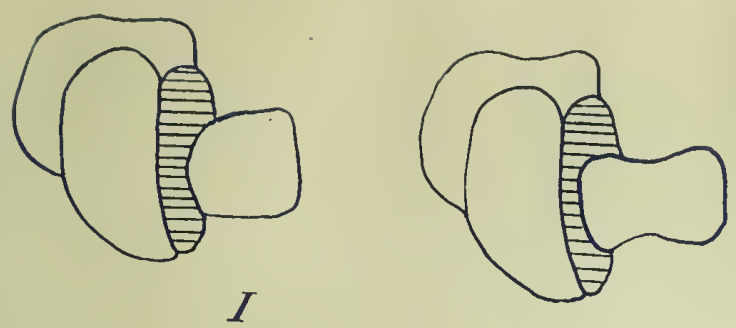

2

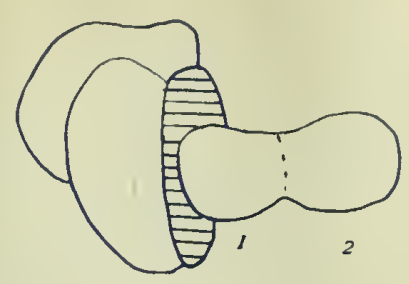

3
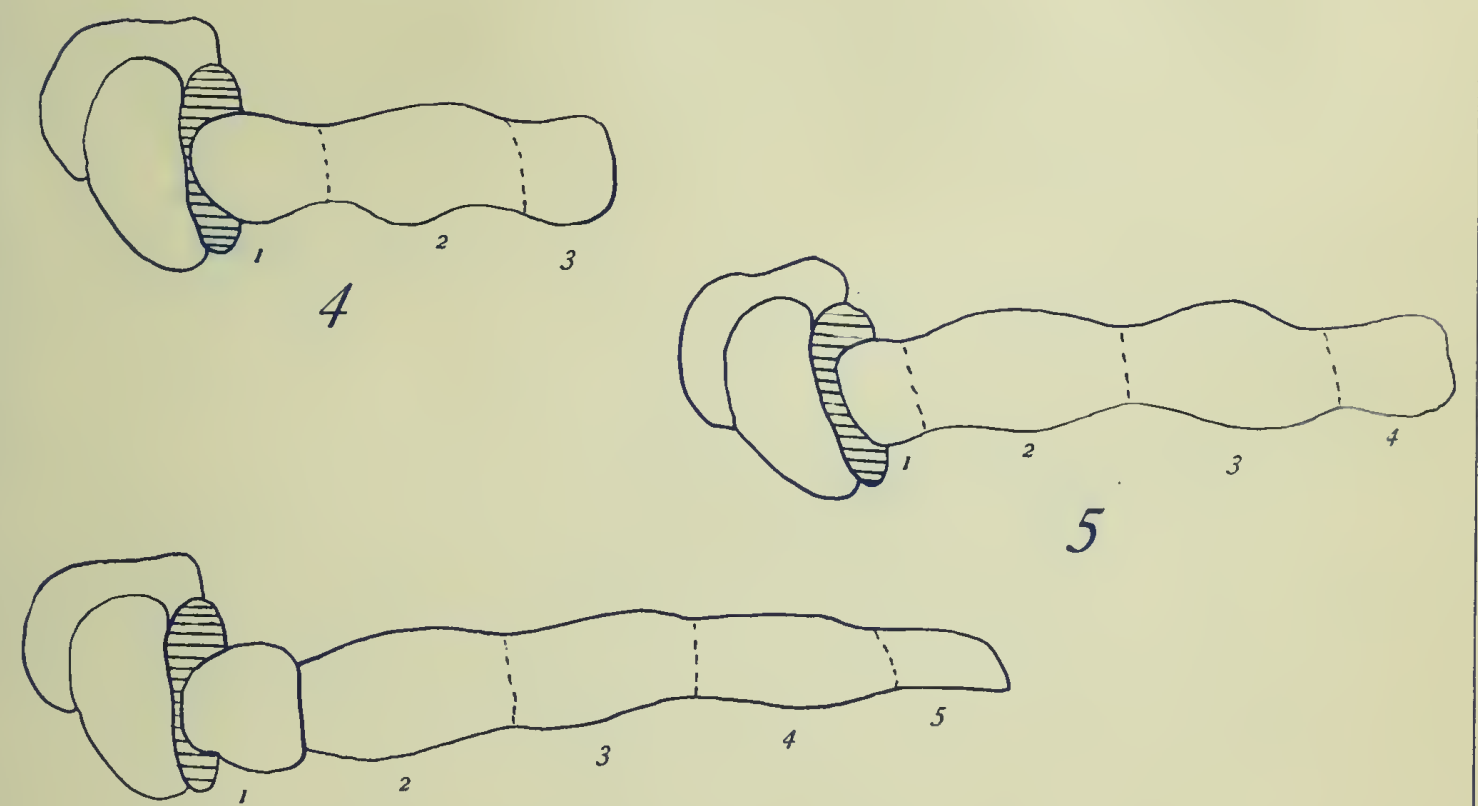

5
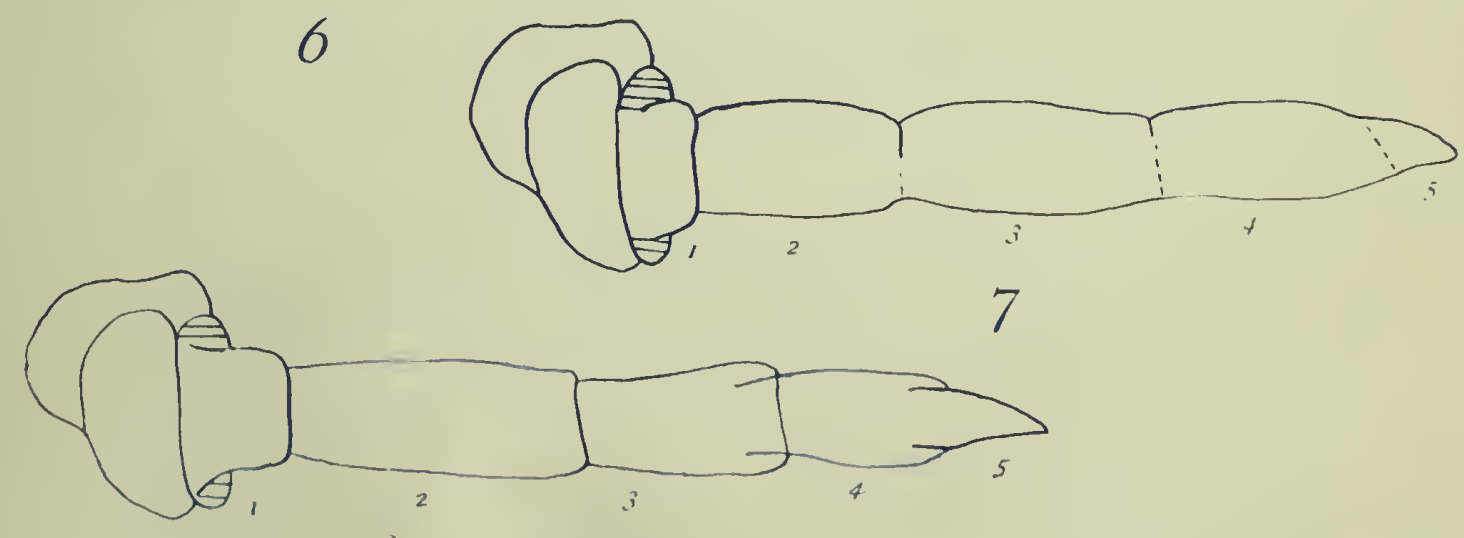

d'

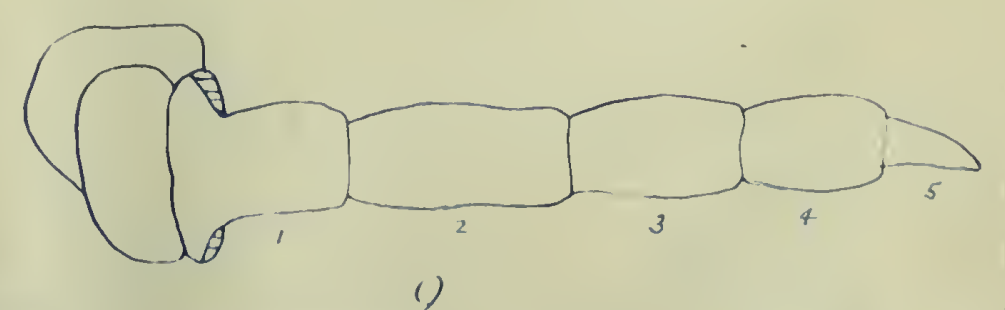



Plate C. Process of Regeneration in Antennules. Description of Figures 1 to 6 .

The antennules are all represented as seen from the dorsal aspect. The dotted lines at the sides of the figures indicate the lerel of cut in each case.

1. A pair of antennules with short inner rami, and welldifferentiated outer ones; constrictions in the basal segments of both and the tip of the right.

2. Inner ramus showing one segment with two constrictions while outer shows four segments - the third longer than the others. No constrictions in the basal segments of the outer ramus.

3. Inner ramus showing four segments with a long third segment, and outer ramus showing four and an unsegmented tip.

4. The third segment in inner ramus slightly longer than others; the basal segment of outer ramus showing constriction. Both inner and outer rami with unsegmented tips.

5. Pair of antennules having five segments in inner rami the third segment of the right being long but that of the left apparently no longer than others. The outer rami show neither constrictions of the basal segments nor unsegmented tips.

6. Pair of antennules cut off at the fourth segment. Outer rami showing increase in length more than inner ones, and segments partitioned off; tips of inner rami showing incomplete segmentation similar to condition in rig. 2 . 



$$
\text { Platec }
$$
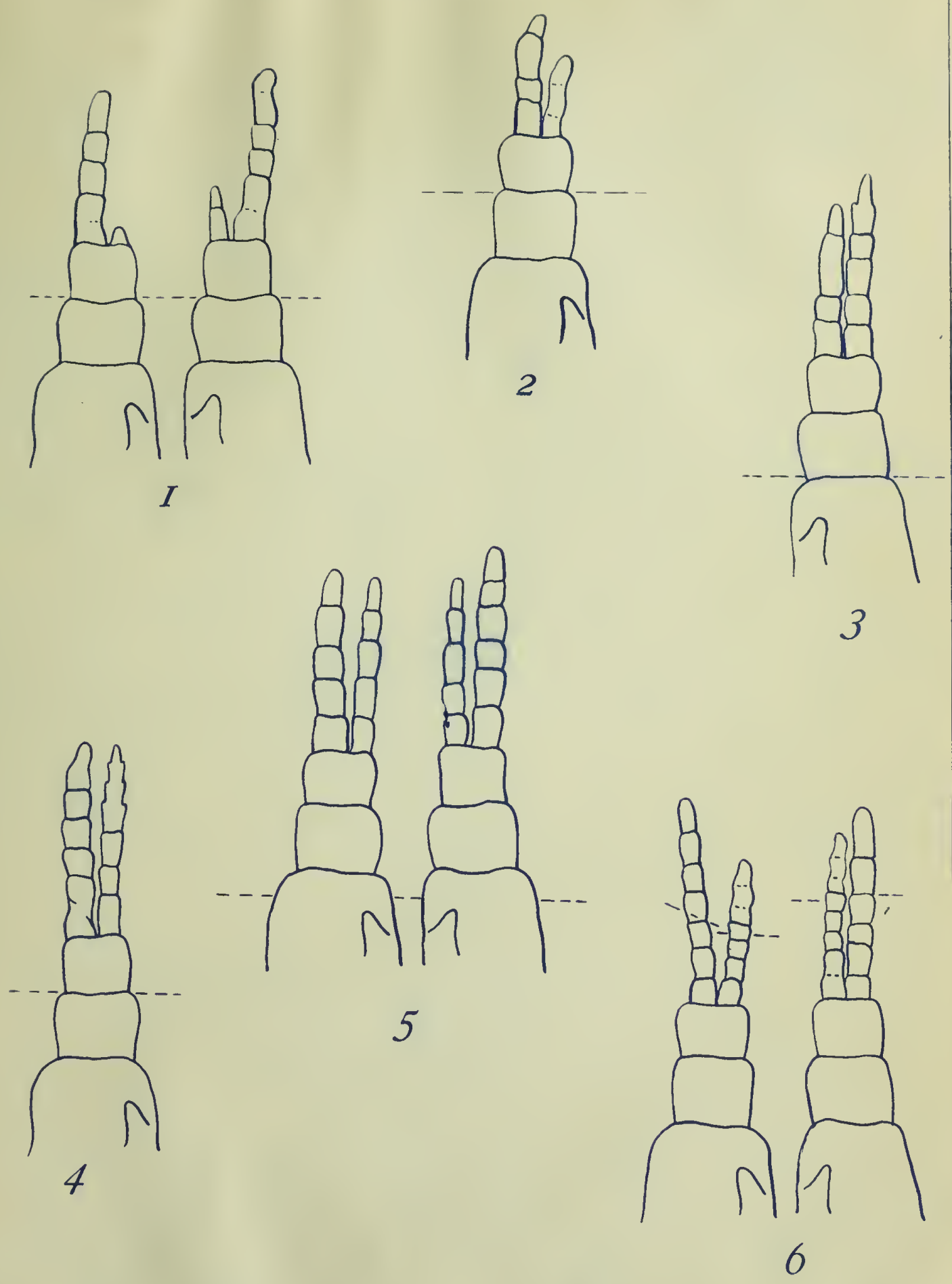

Plate D. Process of Regeneration in Antennae. Description of Figures 1 to 8.

The antennae are all represented as seen from the ventral aspect. The dotted lines at the sides of the figures indicate the level of cut in each case.

1. Antenna 35 days after removal showing very little regeneration to have occurred before the moult.

2. Moult 32 days after operation shows two basal segments and a series of grooves running transversely inward indicating: segmentation.

3. Moult 40 days after removal. Three basal segments formed and grooves indicating segmentation present. Also depressions of a different nature suggesting interpolation.

4. Definite partitions shown 37 days after removal and short depressions are present in each segment.

5. Tip segment long and bearing evidence of further segmentation and two grooves present on the third segment, but no depressions can be detected. 35 days after operation.

6. Antenna after 32 days showing normal three basal segments but no grooves on the third. Slight depressions seen on the fourth and fifth segments and on the tip.

7. No third segment present of much greater length than others but the partitions complete and bearing depressions on most of the segments. Tip partially segmented.

8. Moult 40 days after removal showing no depressions but with one groove on the long third segment. 



\section{Plate D}
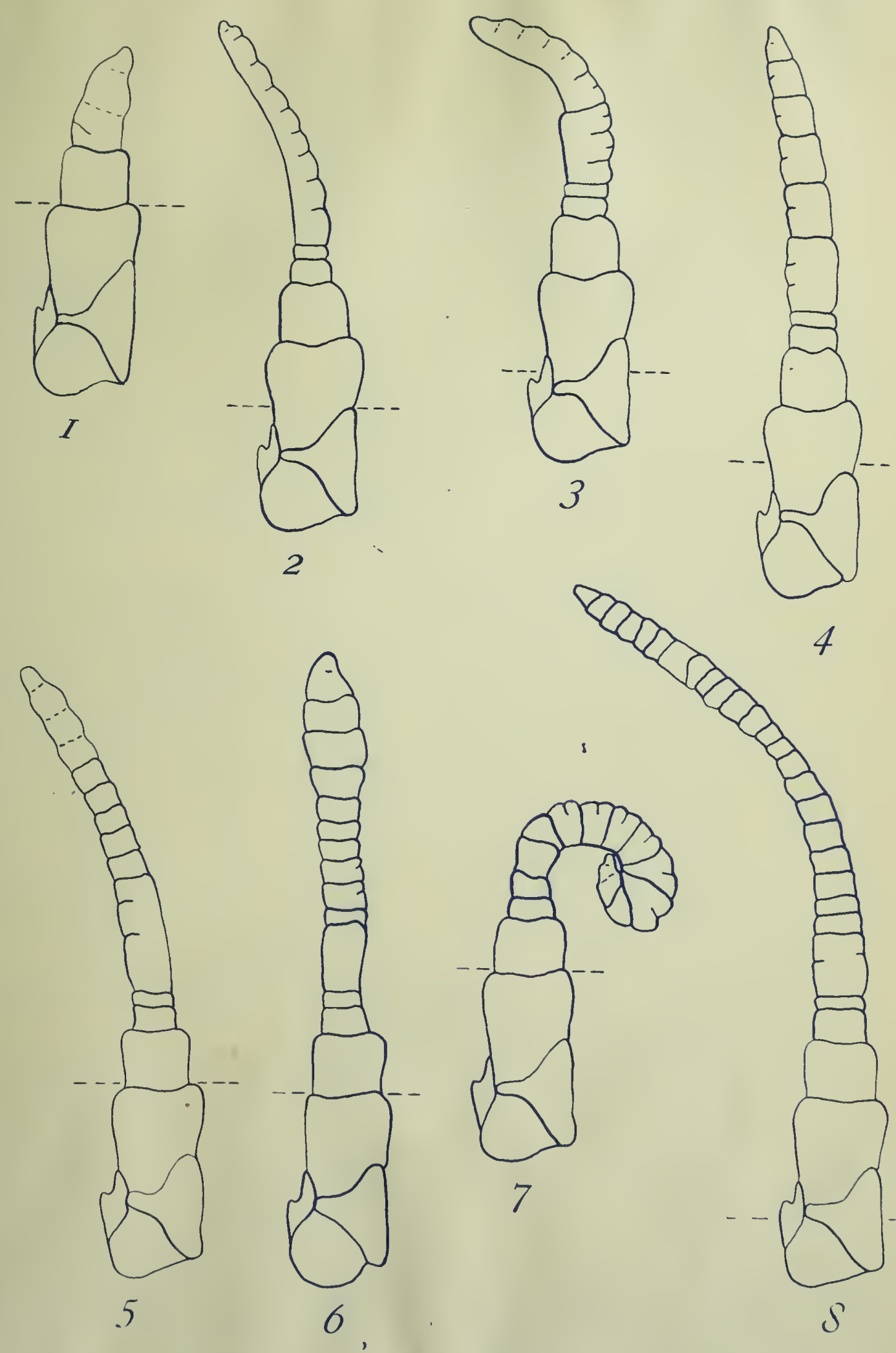



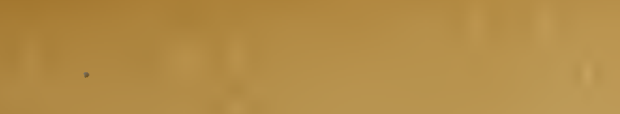

$\cdot$

.
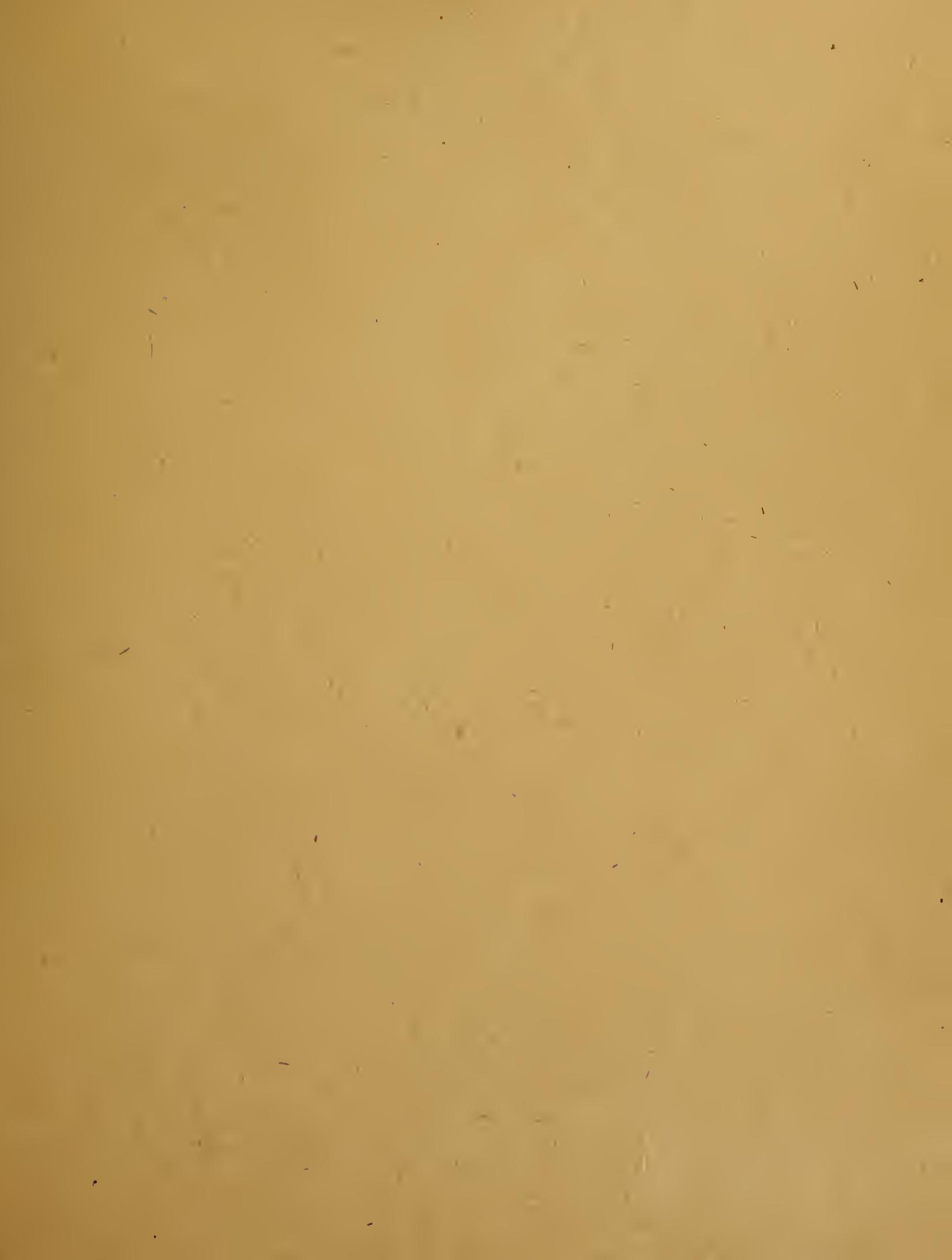
UNIVERSTYY OF ULINOIS-UABANA

||||||||||||||||||||||||||||||||||||||||||||||||||||||||||||||||||||

30112079097439

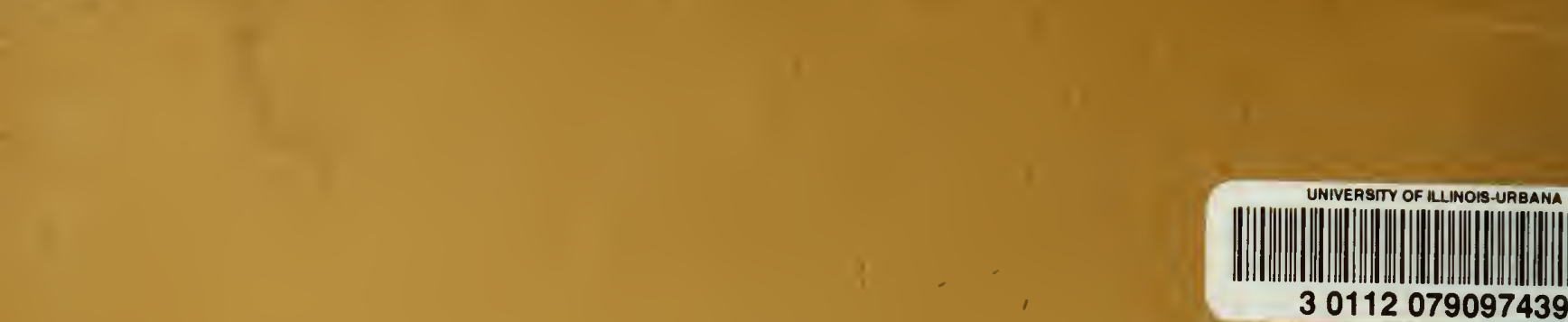

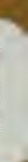

